\title{
BEHAVIORAL PROFILES OF DIFFERENT TYPES OF SOCIAL STATUS IN PRESCHOOL CHILDREN: AN OBSERVATIONAL APPROACH
}

\author{
Francisco Braza \\ Estación Biológica de Doñana, Spain \\ Paloma Braza, M. Rosario Carreras, and José Manuel Muñoz \\ Facultad de Ciencias de la Educación, Spain \\ José R. Sánchez-Martín, Aitziber Azurmendi, Aizpea Sorozabal, \\ AInHOA García AND JaIONE CARDAS \\ Facultad de Psicología, Spain
}

FranciscoBraza,C.S.I.C.(ConsejoSuperiordeInvestigacionesCientificas $=$ SpanishCouncilofScientific Research), Cientifico Titular, Etologia, Biologia Evolutiva, Estación Biológica de Doñana, Spain; Paloma Braza, Professora Titular, Psicologica, Psicologia Evolutive, Facultad de Ciencias de la Educacion, Universidad de Cadiz, Cadiz, Spain; M. Rosario Carreras, Professora Titular, Psicologia, Psicologia Evolutive, Facultad de Ciencias de la Educacion, Universidad de Cadiz, Cadiz, Spain; José Manuel Muñoz, Professor Titular, Psicologia, Personalidad u Evaluacion y Tratamiento Picologico, Facultad de Ciencias de la Educación, Universidad de Cadiz, Cadiz, Spain; José R. Sánchez-Martín, Professor Titular, Procesos Psicologicos, Basicos y su Desarrollo, Psicobiologia, Facultad de Psicologia, Universidad del Pais Vasco, San Sebastian, Spain; Aitziber Azurmendi, Profesora Asociada, Procesos Psicologicos Basicos y su Desarrollo, Psicobiologia, Facultad de Psicologia, Universidad del Pais Vasco, San Sebastian, Spain; Aizpea Sorozabel, Colaboradora Tecnica, Procesos Psicologicos Basicos y su Desarrollo, Psicobiologia, Facultad de Psicologia, Universidad del Pais Vasco, San Sebastian, Spain; Ainhoa García, Becaria Predoctoral Procesos, Psicologhicos Basicos y su, Desarrollo, Psicobiologia, Facultad de Psicologia, Universidad del Pais Vasco, San Sebastian, Spain; and Jaione Cardas, Profesora Asociada, Procesos Psicologicos Basicos y su Desarrollo, Psicobiologia, Facultad de Psicologia, Universidad del Pais Vasco, San Sebastian, Spain.

The authors wish to thank E. Collado for his help in the data analysis and for his comments. They would also like to thank the Head and teachers of the Escuela Josefina Pascual de Cádiz and the parents who enabled them to undertake the observations.

Funding was provided by the Spanish Ministry of Science and Technology/FEDER (BSO200200134).

Appreciation is due to reviewers including: M. Engin Deniz, PhD, Faculty of Technical Education, Department of Education, Selcuk University, Campus 42075, Konya, Turkey, Email: engindeniz@ selcuk.edu.tr; Glenn Weisfeld, PhD, Department of Psychology, Wayne State University, 71 W. Warren, Detroit, MI 48202, USA, Email: weisfeld@sun.science.wayne.edu

Please address correspondence and reprint requests to: Francisco Braza, Estación Biológica Doñana. Apartado 1056, Sevilla 41080, Spain. Email: braza@ebd.csic.es 
The aim of this study was to explore the behavioral profiles of children of various types of social status, in a sample of 54 preschool children ( 15 boys, 39 girls; mean age $=5.15$ years), using an observational method. Popular, rejected, neglected and controversial types of social status were defined by direct observation of the behaviors received by each child from their peers. Behavioral profiles were obtained from the time budget of activities exhibited by each subject during free play time. Popular children showed high levels of hierarchical play and sociability and low levels of all aggression subtypes; rejected children showed high levels in person-directed and seizing object aggressions and did not engage in hierarchical play; neglected children displayed low levels of hierarchical play and sociability and higher than average levels only in seizing object aggression; and controversial children showed high levels of sociability and low levels of hierarchical play. The results highlight the relevance of hierarchical play in social acceptance and its possible effectiveness as an intervention tool.

Keywords: social acceptance, preschool children, social status, behavioral profiles, direct observation.

Clear evidence exists among social development researchers that children's peer relationships play an essential role in furthering social adjustment and competence (Asher \& Coie, 1990; Asher \& Parker, 1989; Hartup, 1983, 1989, 1992); furthermore, peer relationships serve as a protective factor against the impact of adverse family environments and a disadvantaged background (Criss, Pettit, Bates, Dodge, \& Lapp, 2002; Price, 1996). The behaviors displayed in these early social relationships have a decisive influence on the number of opportunities provided for learning the social skills required for social adaptation.

The usual method of measuring future social adjustment is to look at the social status of preschool children. Indeed, it has been well documented that rejected status constitutes a social risk status (Dodge et al., 2003), whereas being popular is considered an advantage for subsequent social adaptation (Moreno, 1999b).

The main question we aim to answer in this study is whether it is possible to identify the behavioral profiles related to acceptance or rejection. Thus, with the aim of identifying the social behaviors related to social adjustment during the preschool period, the study will explore the differences between different types of social status as regards their behavioral profiles.

Social status research has mainly focused on sociometric measures (for a review see Newcomb, Bukowski, \& Pattee, 1993). Thus, the use of sociometric classification could be considered a traditional methodology for the study of social acceptance among peers. One of the most widely used measures has been the peer assessment technique, in which children are asked to nominate classmates as either liked or disliked in play. In short, using this or similar techniques, it is possible to establish different status types with regard to social acceptance among peers. Although the earliest research projects relied on one-dimensional sociometric classification systems (popular or unpopular), later researchers (Coie, Dodge, \& Coppotelli, 1982) developed a two-dimensional sociometric 
classification system (social preference and social impact) which has since played a key role in research focusing on peer relations and social development. In their meta-analytic review, Newcomb et al. (1993) suggested that this standard twodimensional model could be considered a classical approach to the study of peer popularity. This model, which allows a variety of configurations of unpopular children to be identified, has been a key area of progress in the study of children's peer relationships (Rubin, Bukowski, \& Parker, 1998). In addition to the popular and average child, three other social status types have been identified: rejected, neglected, and controversial.

Popularity or rejection at early ages seems to be an important predictor of future social adjustment. Abundant support has been provided for the stability of popular and rejected children over time and across settings (e.g., Cillessen, Bukowski, \& Haselager, 2000). Popular status predicts future social competence, that is, the ability to develop intimate relationships in adolescence, whereas childhood peer rejection is linked to a host of adjustment difficulties in adolescence and adulthood, including aggression, social anxiety, academic failure and school drop-out, delinquency, and psychopathology (for reviews see Coie, Dodge, \& Kupersmidt, 1990; Kupersmidt, Coie, \& Dodge, 1990; Parker \& Asher, 1987).

On the other hand, the status of controversial and neglected children seems to be less stable over time, and some authors believe that they are less at risk from future maladjustment than their rejected counterparts. Nevertheless, being highly active and disruptive, some controversial children may eventually become rejected ones. Although the evidence is scarce, some authors point out that the possible risk of future emotional maladjustment (feelings of depression, social anxiety and learned helplessness) lies in the tendency of these children towards social withdrawal (Goetz \& Dweck, 1980; La Greca, Dandes, Wick, Shaw, \& Stone, 1988; Rubin \& Mills, 1988).

The aforementioned results are based on sociometric methods, in which the choices made by the children are based on the behavior that they observe in the subjects they nominate. In this study we will try to establish different types of social status based on the direct observation of the behaviors received by children from their peers during free play, and to identify the behavioral profiles demonstrated by the children in each of the different social status categories.

In specific terms, and assuming that the observation of the behaviors received by children from their peers during free play enables their social status to be determined, our hypotheses are a) that there are significant differences between the behavioral profiles demonstrated by children of different status, b) that these differences in the behavioral profiles shown may help us identify the behaviors most closely related to acceptance and rejection right from the preschool period. 


\section{METHOD}

\section{Participants}

The sample consisted of 54 preschoolers $(N=54 ; 15$ boys and 39 girls; mean age $=5.15$ years, $S D=0.32$ ) from a state school in a large metropolitan area in Cadiz (Spain). The community served by the school consists primarily of lowermiddle socioeconomic class families, and most parents had completed only secondary-level education. The children's parents had been fully informed of the study and had given their consent.

\section{STUdY AREA}

The study area was a $190 \mathrm{~m}^{2}$ open-air playground containing one drinking fountain, five trees, four stone benches, two goal nets, one large basketball basket and some balls. The study group shared the space with 150 other children aged nine and under, without an adult present, although they were watched by teachers situated at the entrance.

\section{Procedure}

The participants were observed during their free play period at school. The children were filmed with a video camera at least twice a week during their daily half hour free play period throughout a whole academic year (from October to June). The children filmed were unaware of the observers. Behaviors were recorded using focal sampling and continuous recording methods (Martin \& Bateson, 1986), and two independent measures were taken of the behaviors received by the children from their peers and the behaviors in which they themselves engaged.

\section{Social Status}

In order to assign each child a specific type of social status, we considered the affiliative and aggressive behaviors that children received from their peers. Both affiliative and aggressive behaviors were coded in two-way frequency matrices in which peers appeared in the rows and the target children in the columns. In both matrices, the sum of each column represented the total of the affiliative and aggressive behaviors (hereafter AF and AG, respectively) received by each child from all their peers. In accordance with the two dimensions of the sociometric status defined by Peery (1979), we calculated Social Impact as the sum of AF and AG and Social Preference as AF minus AG. In accordance with the system proposed by Coie et al. (1982), five types of social status were identified: a) Popular $=$ children who received a Social Preference of 1.0 or more, a standardized AF score of 0 or more, and a standardized AG score of less than 0; b) Rejected $=$ children who received a Social Preference of less than 
-1.0, a standardized AG score of 0 or more, and a standardized AF score of less than 0 ; c) Neglected $=$ children who received a Social Impact of less than -1.0 , a standardized AF score of less than 0 , and a standardized AG score of less than $0 ;$ d) Controversial $=$ children who received a Social Impact of 1.0 or more, a standardized AF score of 0 or more, and a standardized AG score of 0 or more; and e) Average $=$ all remaining children. The number of subjects assigned to each status varied: 7 were popular, 5 rejected, 13 neglected, 16 controversial, and 13 average.

\section{Behavioral Profiles}

In order to obtain the behavioral profiles of each child we calculated the time spent engaging in the following behavioral dimensions: a) Aggressiveness: In our study, and taking into account the results of a previous study (Muñoz, 2000), we considered three aggression subtypes, person-directed aggression (threatening, smacking, attacking), seizing object aggression, aimed at the retrieval of an object (trying to take an object, taking an object), and defensive object aggression, a defensive reaction to a perceived threatening seizing object aggression (avoiding robbery); b) Sociability. Four subtypes were considered: shared resources, which includes behavioral patterns related to cooperation in the handling of objects and resources (showing, offering an object); physical contact, affiliative behaviors that include physical contact (putting arms round someone, fondling, hugging); social contact, activities that facilitate the initiation and maintenance of affiliative contact (approaching, accompanying); and prosocial behavior, behavior related to providing assistance (helping); and c) Play. Only one subtype was considered, hierarchical play, including pretend play, which implies a group hierarchy for the distribution of roles, and rough-and-tumble play, which has been attributed with a hierarchical character (Pellegrini, 1988; 1993).

To analyze the data, a minimum of two authors recorded the behaviors of each child and, for the inter-observer reliability of the coding system, a Kappa coefficient (Cohen, 1960) was calculated three times during the study period, with the following values being obtained: $0.84,0.91$, and 0.96 respectively.

\section{Statistical AnALYsis}

The variables considered were:

1. Types of social status: four categories were considered in the analysis, (a) popular, (b) rejected, (c) neglected and (d) controversial.

2. Gender of the children.

3. Time spent engaging in the different subtypes of aggressiveness, sociability and play.

Given the limited size of the sample, and bearing in mind that we had, in previous studies, observed the existence of gender differences with regard to 
some behaviors (Braza, Braza, Carreras, \& Muñoz, 1997), a series of two-way ANOVAs was applied to obtain the variation of the behavior in relation to each type of social status and gender. The comparisons of the values of each status were analyzed using a post hoc test (Fisher's Protected LSD). All tests were two-tailed.

\section{RESULTS}

\section{Aggressiveness}

Person-Directed Aggression As shown in Table 1 and Figure 1a, rejected children spent more time engaging in person-directed aggression than did popular children $(p=0.0213$; post hoc test) and neglected ones $(p=0.0214$; post hoc test).

TABLE 1

Analysis of Variance in Person-Directed Aggression for Boys and Girls of Different SOCIAL STATUS TyPES

\begin{tabular}{lrcrc}
\hline & $d f$ & Sum of Squares & $F$ & $p$ \\
\hline Social status types & 3 & 26.631 & 3.380 & 0.0297 \\
Gender & 1 & 26.546 & 10.106 & 0.0032 \\
Social Status x Gender & 3 & 14.540 & 1.845 & 0.1582 \\
Residual & 33 & 86.678 & & \\
\hline
\end{tabular}

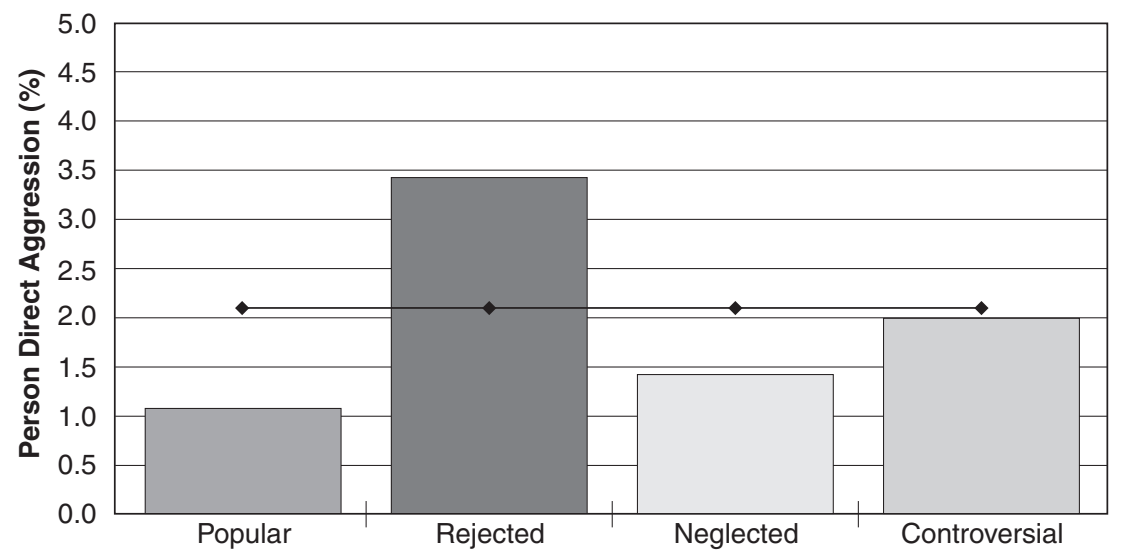

Figure 1a: Proportion of time spent engaging in person-directed aggression by the children of different social status types.

Note: The horizontal line represents the average level. 
Gender differences were observed in the time spent engaged in person-directed aggression with boys spending more time engaged in this aggression subtype than girls ( $M=2.82, S D=2.539$ and $M=1.45, S D=1.403$, respectively). The "Social status types x Gender" interaction was not statistically significant (Table 1).

Seizing Object Aggression The differences between the social status types as regards seizing object aggression were statistically significant (Table 2 and Figure 1b). Rejected children showed the highest level of seizing object aggression, with the proportion of time spent by rejected children engaging in this behavior being significantly higher than that for popular children $(p=$ 0.0204; post hoc test) and controversial children ( $p=0.0238$; post hoc test).

TABLE 2

Analysis of Variance in Seizing ObJect Aggression for Boys and Girls of Different Social Status Types

\begin{tabular}{lrccc}
\hline & $d f$ & Sum of Squares & $F$ & $p$ \\
\hline Social status types & 3 & 3.871 & 3.622 & 0.0230 \\
Gender & 1 & 0.072 & 0.201 & 0.6565 \\
Social Status x Gender & 3 & 4.799 & 4.491 & 0.0095 \\
Residual & 33 & 11.756 & & \\
\hline
\end{tabular}

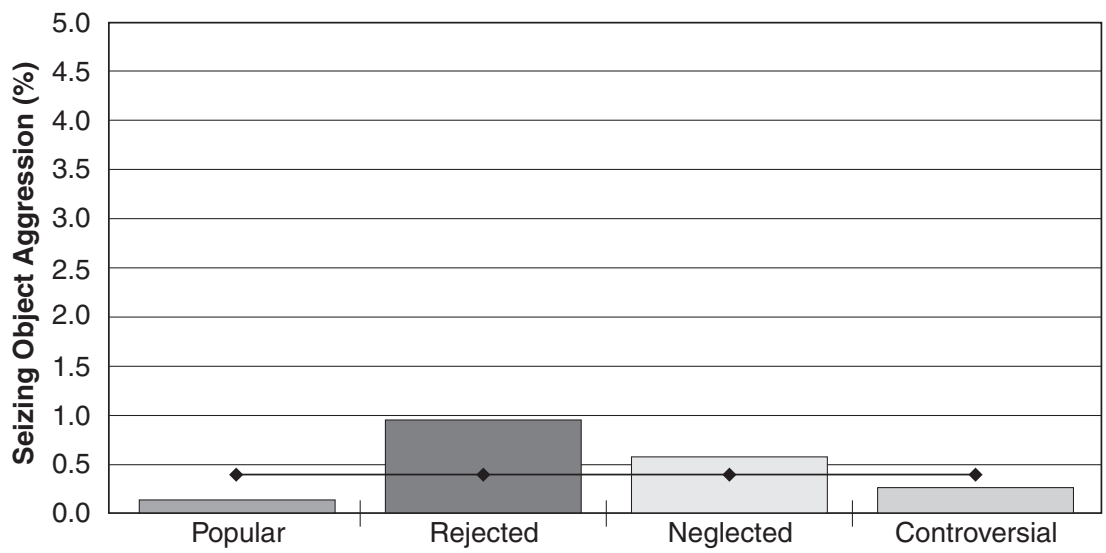

Figure 1b: Proportion of time spent engaging in seizing object aggression by the children of different social status types.

Note: The horizontal line represents the average level.

Although no gender differences were observed in this subtype of aggressive behavior, the "social status types $\mathrm{x}$ gender" interaction was statistically significant (Table 2 and Table 3). Gender differences in seizing object aggression 
were detected only in the case of neglected children, with boys spending a higher proportion of time engaged in this aggression subtype than girls $(M=1.680, S D$ $=1.458$ for boys and $M=0.220, S D=0.561$ for girls). Furthermore, when boys were considered separately, we found that neglected subjects $(M=1.680, S D=$ 1.458) spent a higher proportion of time engaging in seizing object aggression than do their popular $(M=0.001, S D=0.001)$ and controversial $(M=0.232$, $S D=0.217)$ counterparts. Among girls, rejected subjects $(M=1.140, S D=$ $0.971)$ spent a higher proportion of time engaging in this aggression subtype than popular $(M=0.174, S D=0.389)$, neglected $(M=0.220, S D=0.561)$ and controversial $(M=0.260, S D=0.324)$ ones $($ Table 3$)$.

TABLE 3

Comparison of Means in the "Social Status Types x Gender" Interaction of The Analysis of Variance in Seizing ObJect Aggression

\begin{tabular}{llrc}
\hline & & $F$ & $p$ \\
\hline Boys vs Girls & Popular & 0.121 & 0.729 \\
& Rejected & 1.510 & 0.227 \\
& Neglected & 13.809 & $\mathbf{0 . 0 0 0}$ \\
& Controversial & 0.008 & 0.931
\end{tabular}

Boys

$\begin{array}{lrr}\text { Popular vs. Rejected } & 0.192 & 0.664 \\ \text { Popular vs. Neglected } & 9.508 & \mathbf{0 . 0 0 4} \\ \text { Popular vs. Controversial } & 0.216 & 0.645 \\ \text { Rejected vs. Neglected } & 3.894 & 0.056 \\ \text { Rejected vs. Controversial } & 0.018 & 0.893 \\ \text { Controversial vs. Neglected } & 11.036 & \mathbf{0 . 0 0 2}\end{array}$

Girls

$\begin{array}{lll}\text { Popular vs. Rejected } & 5.821 & \mathbf{0 . 0 2 1} \\ \text { Popular vs. Neglected } & 0.020 & 0.889 \\ \text { Popular vs. Controversial } & 0.071 & 0.791 \\ \text { Neglected vs. Rejected } & 6.789 & \mathbf{0 . 0 1 3} \\ \text { Neglected vs. Controversial } & 0.024 & 0.879 \\ \text { Controversial vs. Rejected } & 6.377 & \mathbf{0 . 0 1 6}\end{array}$

\section{SociabiLITY}

Social Contact After controlling gender, a variation in social contact was observed between the different types of social status $\left(F_{(3,33)}=3.373, p=0.0299\right.$, Two-Way ANOVA). Popular children spent a higher proportion of time engaging in social contact than did both rejected $(p=0.0500$; post hoc test) and neglected ( $p=0.0317$; post hoc test) ones (Figure 2a). 


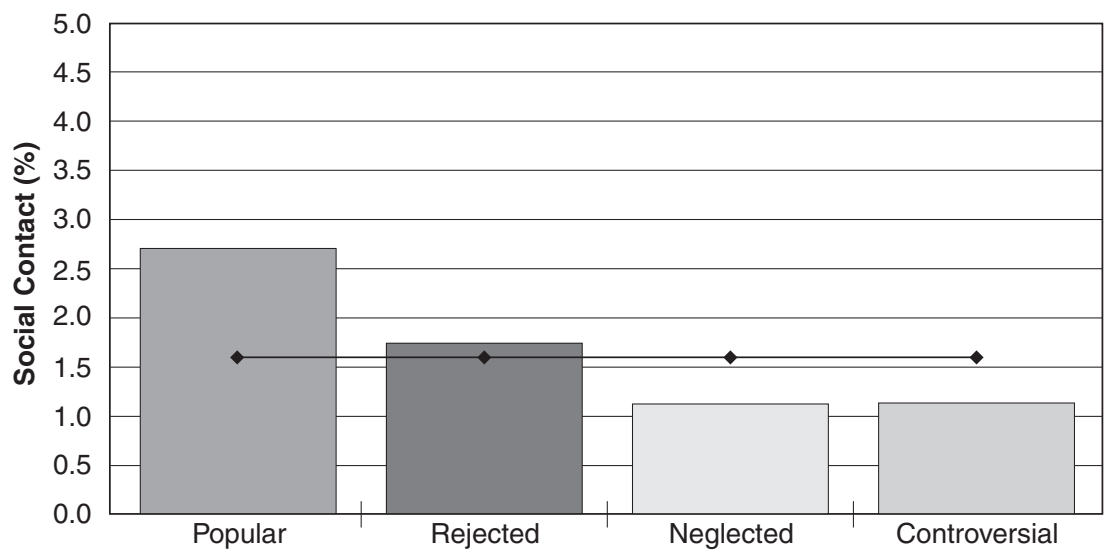

Figure 2a: Proportion of time spent engaging social contact by the children of different social status types.

Note: The horizontal line represents the average level.

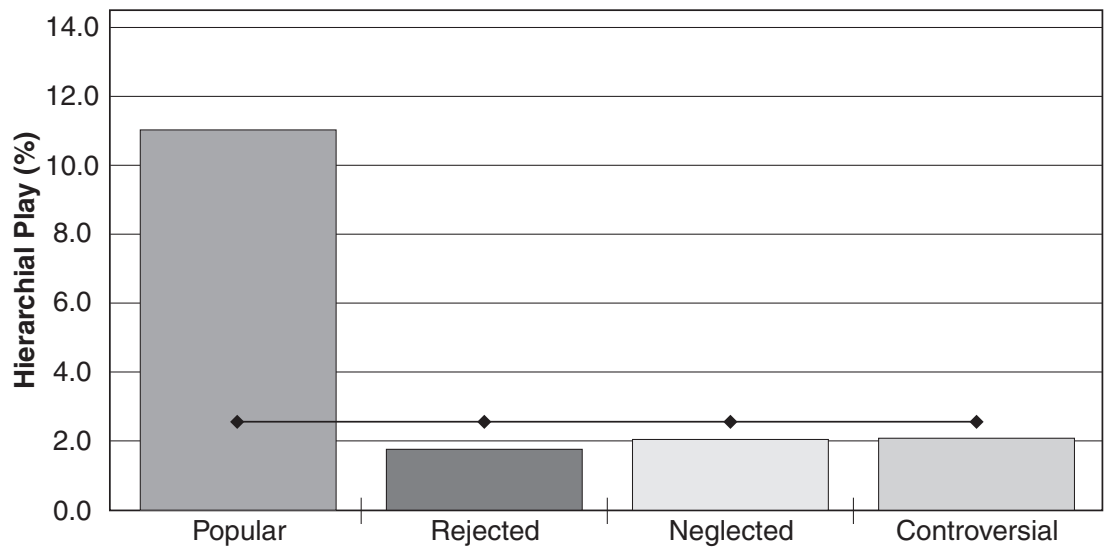

Figure 2b: Proportion of time spent engaging in hierarchical play by the children of different social status types.

Note: The horizontal line represents the average level.

\section{Play}

Hierarchical Play Our results show a significant statistical difference between the children of different types of social status with regard to the time spent in hierarchical play, after gender was controlled $\left(F_{3,36}=4.831, p=0.0062\right.$, Two-Way ANOVA). As shown in Figure 2b, popular children spent a higher proportion of time engaged in this kind of play than did rejected, neglected and controversial ones ( $p=0.0086 ; p=0.0018$ and $p=0.0014$; respectively; post hoc test). 
For the two last behavioral profiles, social contact and hierarchical play, no gender differences $\left(F_{(1,33)}=0.118, p=0.7329 ; F_{(1,36)}=1.401, p=0.2443\right.$, respectively) or "social status types x gender" interaction $\left(F_{(3,33)}=1.807, p=\right.$ $0.1650 ; F_{(3,36)}=0.760, p=0.5248$, respectively) were detected.

For the defensive object aggression, shared resources, physical contact, and prosocial profiles, no statistically significant differences were found in either social status types $\left(F_{(3,33)}=0.697, p=0.5605 ; F_{(3,33)}=1.252, p=0.3069\right.$; $F_{(3,33)}=0.322, p=0.8097 ; F_{(3,34)}=0.644, p=0.5918$, respectively) or gender $\left(_{(1,33)}=0.413, p=0.5250 ; F_{(1,33)}=0.543, p=0.4662 ; F_{(1,33)}=0.906, p=0.3481\right.$; $F_{(1,34)}=0.973, p=0.3309$, respectively). The "social status types $\mathrm{x}$ gender" interaction was not statistically significant in any of these analyses $\left(F_{(3,33)}=\right.$ $0.406, p=0.7495 ; F_{(3,33)}=2.727, p=0.0598 ; F_{(3,33)}=0.313, p=0.8160 ; F_{(3,34)}$ $=0.286, p=0.8349$, respectively).

\section{DISCUSSION}

This study follows the assumption made by Price and Dodge (1989) that direct observation is a useful methodological procedure for the identification and analysis of different social status types. We believe that our results could contribute to the current understanding of some aspects of peer acceptance.

From an evolutionary perspective, the interpretations made of the different roles adopted by members of a social group have always been founded on analyses of the dominance networks established on the basis of aggressive encounters between group members. In this sense, a number of key contributions have been made from an ethological perspective, providing, for example, relevant data regarding dominance-subordination relationships in primates (de Waal, 1986; Rowell, 1974), as well as highlighting revealing links between the behavior of these species and that of humans (Omark, Strayer, \& Freedman, 1980; Weisfeld $\&$ Coleman, 2005). Most studies of simian dominance relationships show that subordinates are worse fighters than their dominant counterparts. Young children, like simians, compete for dominance mainly by fighting (Omark, Omark, \& Edelman, 1975). In the review carried out by Omark, Strayer, and Freedman, the authors demonstrate that dominant individuals tend to be good physical specimens (early maturing, attractive, athletic, and strong); subjects take a lower rank because they are not as tough or strong. Physical traits are salient for dominance from childhood through adolescence (Weisfeld, 1999; Weisfeld \& Coleman, 2005). As a dominance hierarchy stabilizes, the participants get to know their ranks. They do not have to fight as often, since they can predict the outcome of most potential encounters (Savin-Williams, 1976).

However, with children, in addition to dominance networks we also need to take into account both affiliative networks (Moreno, 1999a) and leadership 
networks (Muñoz, Braza, \& Carreras, 2004). In this sense, social status is the result of the subject's participation in these social networks. In the study of social acceptance, it is necessary to consider not only physical characteristics, but also the skills possessed by subjects in handling social relationships with their peers.

With regard to the popular and rejected status types, our results support the hypotheses proposed by other authors (Coie et al., 1982; Coie et al., 1990; Newcomb et al., 1993; Ortiz, Aguirrezabala, Apodaka, Etxebarría, \& López, 2002; Parkhurst \& Asher, 1992; Rubin et al., 1998), suggesting that rejected children present high levels of aggressiveness and low levels of sociability, while popular children show high levels of sociability and lower levels of aggressiveness. We believe that the high level of aggression shown by rejected children may be due to their seeking the benefits of high rank. Popular individuals have less reason to start fights since they already control the resources at stake.

When interpreting our results, it is useful to distinguish between different types of aggression. The aggression subtypes that most help distinguish rejected children are person-directed and seizing object aggression. Both these subtypes are likely to contain high levels of aggressive actions that are either unprovoked or mistakenly believed to be provoked. This latter type of aggressive action has been identified by other authors (Hubbard, 2001; Hubbard et al., 2002; Price \& Dodge, 1989) as behavior characteristic of rejection which is related to hostile attributional biases. All this may point towards the fact that rejected children have difficulties in processing social information. Furthermore, the difficulties they experience in understanding emotions lead them to act more aggressively towards their peers (Arsenio, Cooperman, \& Lover, 2000). This lack of awareness, coupled with their rejected status (Zakriski \& Coie, 1996), leads them to engage in inappropriate and deviant forms of behavior which can result in further reduced levels of peer acceptance. The negative effects of these subtypes of aggressive behavior lead rejected children to remain in this "cycle of failure", reinforcing their status and putting them at high risk of engaging in antisocial behavior in the future (Burleson et. al, 1986; Dodge et al., 2003).

Nevertheless in the case of defensive object aggression, the differences between rejected and popular children were not statistically significant. This type of aggression is the only one that clearly arises as a response to real provocation, which may explain why the differences between rejected children and the other types of status were smaller than for the other aggression subtypes. It is likely that this aggressive behavior contains an assertive component and may be useful in social relationships, providing it is not engaged in exclusively (Carreras, Braza, \& Braza, 2001; Newcomb et al., 1993). We should remember, however, that the level recorded for rejected children in all aggression subtypes was higher than the average. 
With regard to play behaviors, our results show that greater involvement in hierarchical play is a distinguishing factor between rejected and popular children (rejected children are almost never involved in hierarchical play, whereas popular children are practically the only ones that engage in this type of activity). This seems to support the idea that hierarchical play is adaptive, and has a function different from that of other types of games. Early ethological literature on dominance hierarchies suggests that hierarchical play reduces aggressive behavior. Dominance ranks are revealed in the course of this form of play and once the hierarchy is settled, there is less reason to fight since the outcomes of conflicts can be predicted accurately. Moreover, hierarchical play also enables the development of cooperative behavior, which in turn improves relationships between group members.

Rejected children do not engage in hierarchical play, despite the fact that doing so may help them improve their position in the group. Hierarchical play implies the knowledge and acceptance of certain rules and involves sociocognitive abilities that are not required for other types of play and are probably not present in rejected children. For example, Mostow, Izard, Fine, and Trentacosta (2002) observed that in order to maximize children's involvement in pretend play, it is important to provide them with opportunities for practicing empathic responses, and to train them in the use of social skills that may increase the likelihood of their being accepted by their peers.

In short, our results reveal important differences between some of the behaviors demonstrated by popular children and those demonstrated by rejected ones (aggression, social contact, and hierarchical play). These results may be interpreted in light of the adaptive function of said behaviors and/or in light of the proximal mechanisms underlying them. Thus, since they enjoy a good social position in the group, popular children tend to be more gregarious and relaxed, engaging less in aggressive interactions and more in affiliative ones and hierarchical play (which in turn helps them maintain their status). For their part, rejected children engage more in aggressive interactions, seeking to improve their social position within the group. Our results also lead us to adopt an outlook that takes into account the underlying proximal mechanisms, given that the distinction between different aggression subtypes supports the idea that rejected children may lack some of the sociocognitive and emotional skills necessary for correctly interpreting the behavior directed at them by their peers, something which also constitutes a handicap for participating in hierarchical play, the thing that would really help them improve their social status. At this point, we should perhaps recall the words of Tinbergen (1963), who highlighted the usefulness of bearing in mind the convergence of both explanatory perspectives.

Although popular and rejected children have taken up most of our attention with regard to the issue at hand, it is also interesting to deepen our knowledge 
of neglected and controversial subjects. These groups are characterized by being less stable than the others, and may change during the course of the child's development. In this sense, our results reveal a number of characteristic behaviors shown by neglected and controversial children which may help clarify what exactly makes them different from popular and rejected children, and what may favor or hinder their transition to other status types.

In our sample, neglected children showed less aggressiveness than average children, a finding which coincides with previous research (Newcomb et al., 1993; Ortiz et al., 2002). However, in our case, neglected children showed higher levels of seizing object aggression than did average children and did not differ significantly in this type of aggression from rejected children. Although neglected children are less at risk in their sociopersonal development than rejected children (Burleson et al., 1986; Coie et al., 1990), we should remember that studies focusing on emotional or social functioning variables have suggested that, given their tendency towards withdrawal and their shyness, lack of confidence and high anxiety levels during social contact, some neglected children could be at risk of experiencing future emotional maladjustment. If the resulting isolation continues and they are not provided with the opportunity to practice with their peers and learn the social skills they lack, they may eventually join the group of nonaggressive, rejected children (Kupersmidt et al., 1990; Moreno, 1999b; Parker, Rubin, Price, \& DeRosier, 1995). As Arsenio et al. (2000) point out, negative feelings unrelated to specific aggressive behavior can in fact instigate aggression, and the anger, loneliness, and depression experienced by neglected children can lead to future situations of social risk through aggression. The lack of sociocognitive skills of neglected children (Asher \& Coie, 1990; Coie \& Kupersmidt, 1983; Fabes \& Eisenberg, 1992; Hymel, Bowker, \& Woody, 1993; Moreno, 1999b; Ortiz et al., 2002) may increase the likelihood of their resorting to seizing object aggression, the replacement of this behavior by other more prosocial negotiation strategies, as would be expected during normal development. This could also cause neglected children to acquire rejected status as a result of their aggression.

With regard to controversial children, several authors agree that this type of status is defined by high levels of both aggressiveness and sociability (Coie et al., 1990; Newcomb et al., 1993). However, some authors have questioned how children with high levels of aggressiveness can be accepted by some of their peers (Newcomb et al., 1993; Rodkin, Farmer, Pearl, \& Van Acker, 2000), at least in this age group. Our results highlight this question. In order to explain this finding, we believe that attention should be focused not on their aggression but rather on the difficulties they experience in participating in hierarchical play. While - to date - the bipolar sociability-aggressiveness classification has been used as a criterion for distinguishing between different social status types, our 
results suggest the need to take hierarchical play into account in the definition of these types.

In conclusion, it seems that considering hierarchical play in addition to sociability and the different subtypes of aggressiveness (aimed at people, obtaining objects and defending objects) can help us gain a better understanding of differences in social acceptance. Thus, popular children are children with high levels of hierarchical play and sociability and low levels in all aggressiveness subtypes. In contrast, rejected children present high levels of person-directed and seizing object aggression, a moderate level of sociability and a low level of hierarchical play; neglected children, similarly to rejected ones, show low levels of hierarchical play and sociability, but score higher than average children in seizing object aggression; and controversial children present high levels of sociability and low levels of hierarchical play.

Given that this study is exploratory in nature, these conclusions cannot be generalized. However, we believe that our methodological contribution to research in this field could be useful in the selection of appropriate intervention strategies aimed at preventing future social maladjustment, above all during the preschool years, when the possibility of reversing social maladjustment is greater than during the later stages of a child's development. This is due to the fact that at this age, these social status types are not as stable as they become later on, and tend to be more malleable (Berndt \& Hoyle, 1985; Webster-Stratton \& Reid, 2004).

Lastly, with regard to gender differences, several authors (Cassidy, Parke, Butkowsky, \& Braungart, 1992; Denham, McKinley, Couchoud, \& Holt, 1990; Fabes \& Eisenberg, 1992; Hartup, Laursen, Stewart, \& Eastenson, 1988) have already failed to find gender differences in preschool-aged children with regard to their knowledge of emotions, their emotional disposition or their level of acceptance by peers. In our study, despite the fact that boys showed significantly higher levels of person-directed aggression than did girls, the "social status types x gender" interaction was statistically significant only in seizing object aggression. However, we suggest that, given the importance of aggression in the development of social adjustment and the gender differences that exist with regard to the aggressive behavior of children at this age, future research should focus more widely on the effects of the interaction between status types and gender on different forms of aggression.

Based on these results, future researchers should strive to compare the operationality of the status types obtained from direct observation with those obtained using sociometric procedures. Furthermore, future studies could also focus on developing early prevention and intervention programs that would include training in hierarchical play and alternative behaviors to object-oriented aggression. Training in hierarchical play (rough-and-tumble play, and pretend 
play) particularly seems to reduce aggressive behavior and help children develop sociocognitive skills not required in other types of play (for instance, social intelligence, theory of mind). Finally, training in skills such as social negotiation would also help children develop socioemotional qualities and skills (such as empathy).

\section{REFERENCES}

Arsenio, W. F., Cooperman, S., \& Lover, A. (2000). Affective predictors of preschoolers' aggression and peer acceptance: Direct and indirect effects. Developmental Psychology, 36, 438-448.

Asher, S. R., \& Coie, J. D. (1990). Peer rejection in childhood. New York, Cambridge University Press.

Asher, S. R., \& Parker, J. G. (1989). Significance of peer relationship problems in childhood. In B. H. Schneider, G. Attili, J. Nadel, \& R. Weissberg (Eds.), Social competence in developmental perspective. Dordrecht, Holland: Klumer.

Berndt, T. J., \& Hoyle, S. G. (1985). Stability and change in childhood and adolescent friendships. Developmental Psychology, 21, 1007-1015.

Burleson, B. R., Applegate, J. L., Burke, J. A., Clark, R. A., Delia, J. G., \& Kline, S. L. (1986). Communicative correlates of peer acceptance in childhood. Communication Education, 35, 349-361.

Braza, F., Braza, P., Carreras, M. R., \& Muñoz, J. M. (1997). Development of sex differences in preschool children: Social behavior during an academic year. Psychological Reports, 80, 179188.

Cassidy, J., Parke, R., Butkowsky, L., \& Braungart, J. (1992). Family-peer connections: The role of emotional expressiveness within the family and children's understanding of emotion. Child Development, 63, 603-618.

Carreras, M. R., Braza, P., \& Braza, F. (2001). Agonistic behavior and social adjustment in preschool children. Psycothema, 13 (2), 258-262.

Cillessen, A. H., Bukowski, W. M., \& Haselager, G. J. (2000). Stability of sociometric categories. In A. H. Cillessen \& W. M. Bukowski (Eds.), Recent advances in the measurement of acceptance and rejection in the peer system (pp. 75-93). San Francisco: Jossey-Bass.

Cohen, J. (1960). A coefficient of agreement for nominal scales. Educational and Psychological Measurement, 20, 37-46.

Coie, J. D., Dodge, K. A., \& Coppotelli, H. (1982). Dimensions and social status types: A cross-age perspective. Developmental Psychology, 18 (4), 557-570.

Coie, J. D., Dodge, K. A., \& Kupersmidt, J. B. (1990). Peer group behavior and social status. In S. R. Asher \& J. D. Coie (Eds.), Peer rejection in childhood (pp. 17-59). New York: Cambridge University Press.

Coie, J. D., \& Kupersmidt, J. B. (1983). A behavioral analysis of emerging social status in boys' groups. Child Development, 54, 1400-1416.

Criss, M. M., Petit, G. S., Bates, J. E., Dodge, K. A., \& Lapp, A. L. (2002). Family adversity, positive peer relationships, and children's externalizing behavior: A longitudinal perspective on risk and resilience. Child Development, 73 (4), 1220-1237.

de Waal, F. (1986). The integration of dominance and social bonding in primates. The Quarterly Review of Biology, 61, 459-479.

Denham, S., McKinley, M., Couchoud, E., \& Holt, R. (1990). Emotional and behavioral predictors of preschool peer ratings. Child Development, 61, 1145-1152. 
Dodge, K. A., Lansford, J. E., Burks, V. S., Bates, J. E., Pettit, G. S., Fontaine, R., \& Price, J. M. (2003). Peer rejection and social information-processing factors in the development of aggressive behavior problems in children. Child Development, 74 (2), 374-393.

Fabes, R. A., \& Eisenberg, N. (1992). Young children's coping with interpersonal anger. Child Development, 63, 116-128.

Goetz, T. E., \& Dweck, C. S. (1980). Learned helplessness in social situations. Journal of Personality and Social Psychology, 39, 246-255.

Hartup, W. W. (1983). Peer relations. In P. H. Mussen (Series Ed.) \& E. M. Hetherington (Ed.), Handbook of child psychology: Vol. 4. Socialization, personality, and social development (pp. 103-196). New York: Wiley.

Hartup, W. W. (1989). Social relationships and their developmental significance. American Psychologist, 44, 120-126.

Hartup, W. W. (1992). Peer relations in early and middle childhood. In V. Van Hasselt \& M. Hersen (Eds.), Handbook of social development: A lifespan perspective (pp. 257-281). New York: Plenum Press.

Hartup, W. W., Laursen, B., Stewart, M., \& Eastenson, A. (1988). Conflict and the friendship relations of young children. Child Development, 59, 1590-1600.

Hubbard, J. A. (2001). Emotion expression processes in children's peer interaction: The role of peer rejection, aggression, and gender. Child Development, 72 (5), 1426-1438.

Hubbard, J. A., Smithmyer, C. M., Ramsden, S. R., Parker, E. H., Flanagan, K. D., Dearing, K. F., Relyea, N., \& Simons, R. F. (2002). Observational, physiological, and self-report measures of children's anger: Relations to reactive versus proactive aggression. Child Development, 73 (4), 1101-1118.

Hymel, S., Bowker, A., \& Woody, E. (1993). Aggressive versus withdrawn unpopular children: Variation in peer and self-perceptions in multiple domains. Child Development, 64, 879-896.

Kupersmidt, J. B., Coie, J. D., \& Dodge, K. A. (1990). Predicting disorder from peer social problems. In S. R. Asher \& J. D. Coie (Eds.), Peer rejection in childhood (pp. 274-305). NY: Cambridge University Press.

La Greca, A. M., Dandes, S. K., Wick, P., Shaw, K., \& Stone, W. L. (1988). Development of the Social Anxiety Scale for Children: Reliability and concurrent validity. Journal of Clinical Child Psychology, 17, 84-91.

Martin, P., \& Bateson, P. (1986). Measuring behavior: An introductory guide. Cambridge: Cambridge University Press.

Moreno, M. C. (1999a). Desarrollo y conducta social de los 2 a los 6 años. In J. Palacios, A. Marchesi, \& C. Coll (Eds.), Desarrollo Psicológico y Educación: Vol 1. Psicología Evolutiva (pp. 305-326). Madrid: Alianza Editorial.

Moreno, M. C. (1999b). Desarrollo y conducta social de los 6 años a la adolescencia. In J. Palacios, A. Marchesi \& C. Coll (Eds.), Desarrollo Psicológico y Educación: Vol 1. Psicología Evolutiva (pp. 405-430). Madrid: Alianza Editorial.

Mostow, A. J., Izard, C. E., Fine, S., \& Trentacosta, C. J. (2002). Modelling emotions, cognitive, and behavioural predictors of peer acceptance. Child Development, 73 (6), 1775-1787.

Muñoz, J. M. (2000). Social behavior analysis of preschool children during free play time at school: A proposal of modelling. Cádiz, Spain: Cádiz University.

Muñoz, J. M., Braza, F., \& Carreras, M. R. (2004). Controlling relatioships in preschool children. International Journal of Behavioral Development, 28 (5), 444-448.

Newcomb, A. F., Bukowski, W. M., \& Pattee, L. (1993). Children's peer relations: A metaanalytic review of popular, rejected, neglected, controversial, and average sociometric status. Psychological Bulletin, 113, 99-128. 
Omark, D. R., Omark, M., \& Edelman, M. S. (1975). Formation of dominance hierarchies in young children: Action and perception. In T. Williams (Ed.), Psychological anthropology (pp. 289-315) The Netherlands: Mouton.

Omark, D. R., Strayer, F. F., \& Freedman D. G. (1980). Dominance relations: An ethological view of human conflict and social interaction. New York: Garland STM Press.

Ortiz, M. J., Aguirrezabala, E., Apodaka, P., Etxebarría, I., \& López, F. (2002). Características emocionales, funcionamiento social y satisfacción social en escolares. Infancia y Aprendizaje, 25 (2), 195-208.

Parker, J. G., \& Asher, S. R. (1987). Peer relations and later personal adjustment: Are low accepted children 'at risk'? Psychological Bulletin, 102, 357-389.

Parker, J. G., Rubin, K. H., Price, J. M., \& DeRosier, M. E. (1995). Peer relationships, child development, and adjustment: A developmental psychopathology perspective. In D. Cicchetti \& D. Cohen (Eds.), Developmental Psychopathology: Vol. 2. Risk, Disorder and adaptation (pp. 96-161). New York, Wiley.

Parkhurst, J. T., \& Asher, S. R. (1992). Peer rejection in middle school: Subgroup differences in behavior, loneliness and interpersonal concerns. Developmental Psychology, 28, 231-241.

Pellegrini, A. D. (1988). Elementary-school children's rough-and-tumble play and social competence. Developmental Psychology, 244, 802-806.

Pellegrini, A. D. (1993). Boys' rough-and-tumble play, social competence and group composition. British Journal of Developmental Psychology, 11, 237-248.

Peery, J. C. (1979). Popular, amiable, isolated, rejected: A reconceptualization of sociometric status in preschool children. Child Development, 50, 1231-1234.

Price, J. M. (1996). Friendships of maltreated children and adolescents: Contexts for expressing and modifying relationship history. In W. M. Bukowski, A. F. Newcomb, \& W. W. Hartup (Eds.), The company they keep. Friendship in childhood and adolescence (pp. 262-285). Cambridge: Cambridge University Press.

Price, J. M., \& Dodge, K. A. (1989). Reactive and proactive aggression in childhood: Relations to peer status and social context dimensions. Journal of Abnormal Psychology, 17 (4), 455-471.

Rodkin, P. C., Farmer, T. W., Pearl, R., \& Van Acker, R. (2000). Heterogeneity of popular boys: Antisocial and prosocial configurations. Developmental Psychology, 36, 14-24.

Rowell, T. (1974). The concept of social dominance. Behavioral Biology, 11, 131-154.

Rubin, K. H., Bukowski, W. M., \& Parker, J. G. (1998). Peer interactions, relationships and groups. In W. Damon (Series Ed.), N. Eisenberg (Ed.), Handbook of child psychology: Vol 3.Social, emotional and personality development (pp. 619-700). New York: Wiley.

Rubin, K. H., \& Mills, R. L. (1988). The many faces of social isolation in childhood. Journal of Consulting and Clinical Psychology, 56, 916-924.

Savin-Williams, R. C. (1976). An ethological study of dominance formation and maintenance in a group of human adolescents. Child Development, 47, 972-979.

Tinbergen, N. (1963). On aims and methods of ethology. Zeitschrift für Tierpsychologie, 20, 410433.

Webster-Stratton, C., \& Reid, M. J. (2004). Strengthening social and emotional competence in young children. The foundation for early school readiness and success. Incredible years classroom social skills and problem-solving curriculum. Infants and young children, 17 (2), 96-113.

Weisfeld, G. E. (1999). Evolutionary principles of human adolescence. New York: Basic Books.

Weisfeld, G. E., \& Coleman, D. K. (2005). Further observations on adolescence. In R. L. Burgess \& K. MacDonald (Eds.). Evolutionary perspectives on human development (pp. 331-357). CA: Sage Publications.

Zakriski, A. L., \& Coie, J. D. (1996). A comparison of aggressive-rejected and nonaggressive-rejected children. Interpretations of self-directed and other-directed rejection. Child Development, 67, 1048-1070. 
